
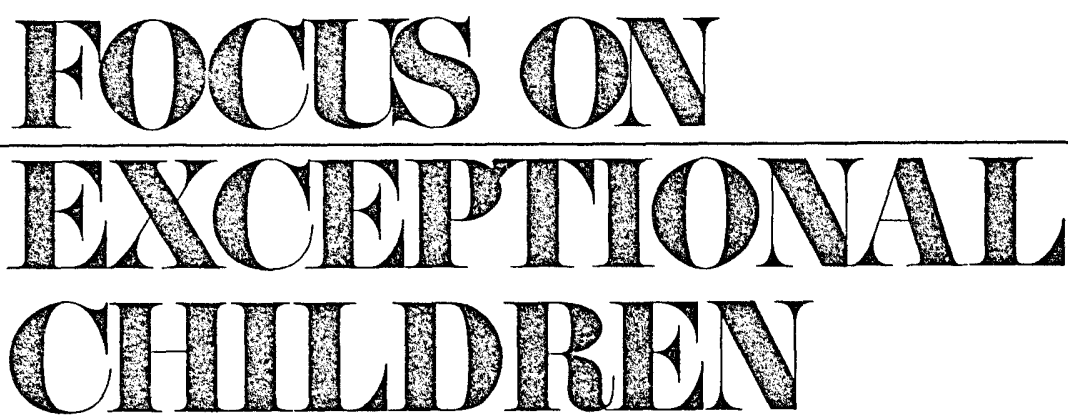

\title{
Assessment of Young Children with Special Needs
}

Jeanne M. McCarthy, Kathryn A. Lund, and Candace S. Bos

Those concerned with the teaching of young handicapped children are being bombarded by conflicting messages from a variety of professional fields. The growing national priority on early identification, screening, diagnosis, and treatment has emphasized the need for more intensive and specific diagnostic or assessment procedures, at earlier and earlier ages. Investigators in pediatrics, neonatology, psychology, and education are trying to define the variables in each of the developmental areas that will reliably identify the instructional needs of children who need intervention in the early months or years of life. New assessment devices are appearing in large numbers, to augment the sizable number of standardized tests suitable for the early childhood population.

The authors have been involved with development of the Arizona Basic Assessment and Curriculum Utilization System (ABACUS). This, basically, is an intervention system representing an early education program for young handicapped children functioning in the developmental age range from 2 to $51 / 2$ years. As part of the overall program, the Assessment component follows a philosophy consistent with:

- an emphasis on the needs of the child across all components of the ecological system in which he or she lives.

- an emphasis on instruction as the primary purpose of assessment, and a corresponding deemphasis on etiology (origin) or classification.

- A view of assessment as an ongoing process best done in the teachinglearning situation - thus moving the focus from the psychologist to the teacher and the locus from the specialist's office to the classroom.

- An emphasis on functional levels rather than on quantified statements of performance based on extrapolations from limited samples of behavior.

The authors are associated with the Department of Special Education, College of Education, University of Arizona. They are also developers of the Arizona Basic Assessment and Curriculum Utilization System ( $A B A C U S)$ for young handicapped children, a project undertaken as part of the Handicapped Children's Early Education Program of the Special Education Programs (SEPS), U.S. Office of Education.

๑) Love Publishing Company, 1983 


\section{AN ECOLOGICAL APPROACH TO ASSESSMENT}

In the assessment of young exceptional children, the traditional view of assessment, or diagnosis, must be broadened to include the child's total ecological system. Rather than asking, "What is wrong with this child? . . What are his (her) strengths and weaknesses?" the questions in this approach are, "What does this child need in order to optimize his (her) growth and development? ... What does he (she) need from each component of his (her) ecosystem to survive and thrive, to become the most socially competent human being possible?" The assessment process must include assessment of the child's service needs and the needs and strengths of significant others in his or her environment. A nutritional assessment may be more important than a cognitive assessment to some children. Assessment of the mother's ability to cope, or her need for respite care, may be more critical than any other type of assessment.

\section{THE PURPOSE OF ASSESSMENT}

The purpose of assessment is primarily for instructional purposes and to establish the child's present level of performance in each of the areas considered important

FOCUS ON EXCEPTIONAL CHILDREN (ISSN 0015-5IIX) (USPS 203-360) is published monthly except June, July, and August as a service to teachers, special educators, curriculum specialists, administrators, and those concerned with the special education of exceptional children. This journal is abstracted and indexed in Exceptional Child Education Resources, and is also a vailable in microform from Xerox University Microfilms, Ann Arbor, Michigan. Subscription rates, $\$ 15.00$ per year. Copyright 1983, Love Publishing Company. All rights reserved. Reproduction in whole or part without written permission is prohibited. Printed in the United States of America. Second class postage is paid at Denver, Colorado. POSTMASTER: Send address changes to:

$$
\begin{gathered}
\text { Love Publishing Company } \\
\text { Executive and Editorial Office } \\
1777 \text { South Bellaire Street } \\
\text { Denver, Colorado } 80222 \\
\text { Telephone (303) } 757-2579
\end{gathered}
$$

\section{EDITORIAL BOARD}

Edward L. Meyen

University of Kansas

Richard J. Whelan

University of Kansas Medical Center for him or her to learn. The assessment process permits the teacher to specify objectives, strategies, and activities keyed to the child's level of performance. In addition, assessment information is useful in making placement decisions and in the evaluation process - both evaluation of program effectiveness and evaluation of child progress. In evaluating child progress, comparing the child with himself or herself, as well as with nonhandicapped peers, has been found useful. With these purposes in mind, both criterion-referenced assessment instruments and norm-referenced instruments may have to be utilized.

\section{THE TEACHER'S ROLE IN THE ASSESSMENT PROCESS}

In the ABACUS model, assessment is viewed as an ongoing process. The teacher is involved in all facets of the process - as the generator of data on criterionreferenced instruments, as an adjunct to the psychologist responsible for the norm-referenced intelligence testing, and as a sophisticated consumer of norm-referenced data. Further, observation of the child in the process of learning may yield information critical to the assessment process.

In addition to the teacher's involvement in standardized testing, his or her role in the use of criterionreferenced tests becomes even more critical because of the nature of these tests. The teacher, with his or her detailed knowledge of what the child can do, is the most logical person to utilize criterion-referenced instruments. The teacher is in the best position to judge when to test the child, to select the time at which he or she is functioning best, and to determine appropriate entry points on the assessment device. In the ABACUS as long as two or three weeks may be necessary to complete the process, with short daily sessions of five to 10 minutes interspersed in the daily program. This would be impossible for anyone not in daily contact with the child.

Because the assessment of young handicapped children is an art, not a science, it must be done with extreme care, not on a one-shot basis in surroundings that are strange to the child. Also, testing children in familiar surroundings, usually a corner of the classroom, has been found most fruitful. In some cases, the teacher might have to interpret verbal or signed responses that may not be totally intelligible. In all cases, the teacher is the major translator of data from tests administered by 
the support staff into each child's instructional program. The total assessment process in the ABACUS encompasses clinical observations, clinical teaching, and normreferenced and criterion-referenced testing. The classroom teaching staff plays an important role in all three phases, complementing and enhancing the contribution of support staff traditionally assigned these functions.

\section{ASSUMPTIONS BASIC TO THE ASSESSMENT OF YOUNG HANDICAPPED CHILDREN}

Implicit in the approach to assessment of young children in the ABACUS model are the following basic assumptions:

1. The word "assessment," rather than "diagnosis," is used in relation to instruction because it places emphasis on the current level of developmental functioning. "Diagnosis" is best left to the medical model, since a medical diagnosis leads to definitive statements about etiology, clinical symptomatology, treatment, and prognosis, whereas "assessment" leads to an appropriate educational program.

Educational and psychological testing provide little or no information about etiology, some about clinical symptomatology, little or none about treatment, and none about prognosis. Rather than "diagnosing" a problem, we should be describing a preschool child's current level of functioning in such a way that the assessment leads to appropriate instructional programming.

2. The testing situation elicits only a limited sample, at best, of the child's behavior. In many cases, the behavior is better described than quantified or labeled.

3. Intelligence develops out of continuous interaction between the child and his or her environment. This dynamic commitment to the educability of intelligence must be uppermost in the mind of anyone involved in assessing young children. Intelligence is not static. It may fluctuate in response to environmental stimulation. Assessing the environment may be an important adjunct to assessing the child.

4. Given the instability of the IQ in young children and their response to environmental stimulation, the traditional labels should be used with extreme caution, if at all. Labeling a three-year-old as educable mentally retarded or learning disabled appears to be unwarranted because of the permanence implied in these labels.

A term such as "developmentally delayed" is preferable to describe the child's level of functioning at the moment and does not convey the permanence inherent in most other labels. Labeling before the age of six or seven, for most of the "soft" categories of handicapping conditions, should be avoided if possible. In any case, the label should be as far removed as possible from the child. Maturation, time, and spontaneous recovery of function may make liars of the most competent assessors.

5. The idea that every child is learning something every waking moment is important to the educator of preschool children. Children are processing all environmental stimuli with or without our being aware of it.

6. The younger the child, the less reliable will be the predictions across all dimensions measured. The purpose of early intervention is to change the outcome for each child, thus reducing the predictive reliability of assessment instruments.

7. The more complex the multiplicity of handicaps, the more difficult, sensitive, and demanding will be the assessment process.

8. If three or four years in the home environment have not helped a child develop at a rate commensurate with peers, recommending a change in his or her environment makes good sense. Nursery school, a Head Start program, or a special preschool program are among the viable options, matching the intensity of service to the severity of the delay.

9. The functioning of a child at home, on the bus, on the playground, with peers, is more relevant than his or her performance in the specialist's office and has to be considered in the assessment process.

10. Screening procedures for young children should not be implemented until a service plan has been carefully thought out. Unless service is to follow, identifying and labeling children may prove to be a disservice. The kinds of service and the numbers of children for whom service is available will dictate details of the screening procedures.

11. The task of assessment is to pinpoint where children are, what they can do, what they are 
doing. Little emphasis should be placed on what they cannot do. This is especially true for severely and profoundly involved children. After describing what the child can do, the development of an instructional program is relatively simple, since the program is to be built upon what he or she can do, using sequenced steps to teach new skills.

\section{PREVALENCE OF HANDICAPPING CONDITIONS AMONG PRESCHOOL CHILDREN}

When planning a total assessment process for preschool handicapped child ren, the numbers of child ren to be served at each step of the process should be estimated. A review of the literature on the prevalence of handicapping conditions among children under five years of age reveals a dearth of reliable data useful to the person responsible for program development. Because of variability in criteria in the reported studies, prevalence figures range from $3 \%$ to $17 \%$ of the total preschool population in need of special education programming in the preschool years. The lower figures have been found in studies of physically handicapped children, excluding the categories of speech impaired, emotionally handicapped, educable mentally retarded, and learning disabled.

The U.S. Office of Education, Special Education Programs, has limited the percentage of the total population to be counted for reimbursement (under Public Law 94-142) to $12 \%$ of the school-aged population. The actual percentage of children being served is $8-9 \%$, with some variability between states. Given these figures, we can probably estimate that $5-10 \%$ of the preschool population of an average school district would be in need of intervention because of a handicapping condition. Sociocultural variations, as well as socioeconomic factors, require these estimates to be increased or decreased accordingly.

Using the "guesstimates," a school district of 10,00015,000 children, with 1,000 three-year-olds and 1,000 four-year-olds, could reasonably expect between 100 and 200 children to be eligible for a preschool program, across all categories of the handicapped. Some sensory impaired children may already have been placed in a state program for the deaf, blind, or multiply handicapped. Some of the mildly involved children may be viewed as "immature" and not identified as handicapped. If the community is characterized by closely knit, ex- tended families, the preschoolers in need of special services may not surface until they reach kindergarten age. If the community is economically deprived, the prevalence of handicapping conditions may be higher.

As a general rule of thumb, we may start with a $10 \%$ prevalence estimate and cut it in half for a new program, planning at the $5 \%$ level until the program becomes established. In a poverty level community the figure could be safely estimated at $15-20 \%$ for purposes of planning to meet the needs of the handicapped. Larger numbers of children initially identified during the first steps of the screening process will be gradually reduced to a lower figure.

\section{A TOTAL ASSESSMENT PROCESS FOR PRESCHOOL HANDICAPPED CHILDREN}

Assessment as used in the ABACUS calls for six steps, which are briefly outlined in this article.

\section{Step 1: Screening}

Screening is defined as a process to determine if $a$ problem exists. Some of the important questions to be asked before instituting a screening program are as follows:

- What age group will be served?

- What kinds of handicapping conditions will be served?

- What will you do with the children once you find them?

- What philosophy underlies your intervention approach?

- Which curriculum is most appropriate for the children you will find?

- What instructional methodology is most appropriate?

- What will be the organizational structure of the program?

- Where will it be?

- How many persons will be needed for the screening process, and who will be utilized (volunteers, paraprofessionals)?

- To which clinics, agencies, or professionals will the parents be referred for further diagnosis of the child? 


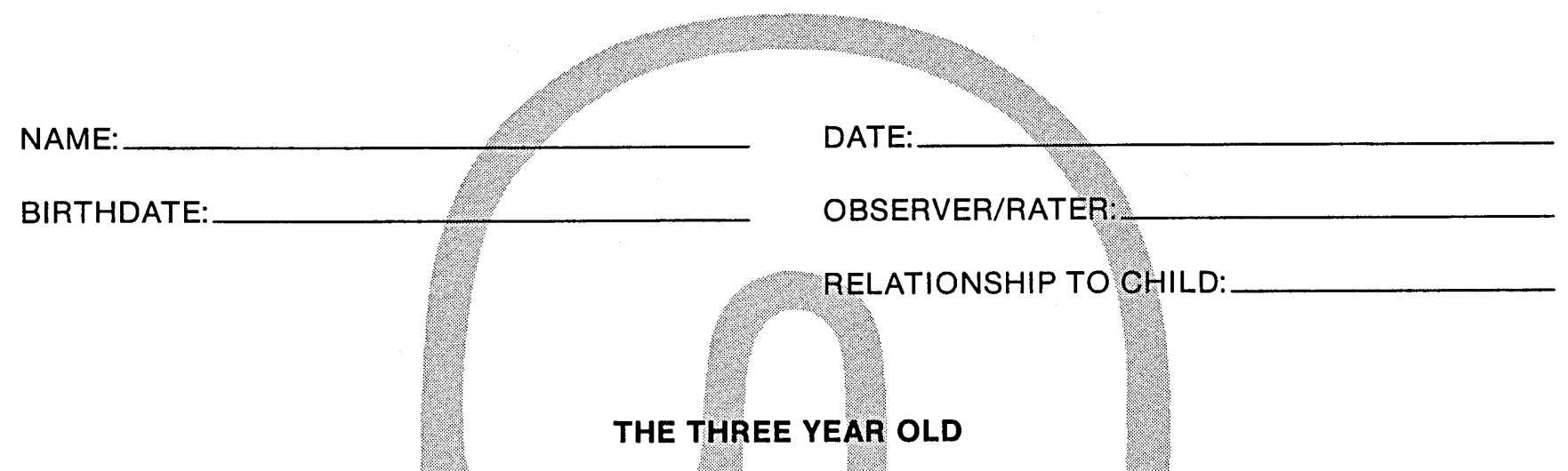

Check child's performance in each skill on the following pages. After checking the child's skills within an area, total the number of Can Do responses. Write this number in the box marked TOTAL on each page. Then transfer that number to the column on this page that includes the TOTAL in each developmental area.

Do you consider this child to be a:

slow learner

average learner

rapid learner 
- How many children will be identified as having special needs in screening?

- How much will the screening program cost? How about the cost of diagnosis? Assessment?

- Who will pay for it?

In the ABACUS, the screening is divided into two levels with two instruments - the PreABACUS Screening Scale I (PASS I) and the PreABACUS Screening Scale II (PASS II). The face sheets of these instruments are shown here as Figures 1 and 2.

PASS I is a checklist for behavioral observations. Little professional time is required to use or score this checklist, so the cost per child is relatively low. PASS I has been developed for ages 2, 3 (as indicated by Figure 1), 4, and 5. Each checklist consists of 10 items in the five developmental areas of the ABACUS to be rated by the parent or care-giver - Body Management, Self-Care, Communication, Pre-Academics, and Socialization.

Children functioning in the lower quartile for their chronological age in any of the developmental areas would be singled out for further consideration. A rough estimate of the numbers being singled out at this stage of the screening process depends upon the characteristics of the total population, with higher prevalence figures for low socioeconomic groups. In normal populations $15 \%$ of the population might appear to need further study at this point.

These children would be candidates for the more intensive screening of the PASS II, which contains 60 selected items from the full ABACUS that are considered to be marker variables in each developmental area. PASS II would be administered to the smaller subset of the total population - only to those children who appear to have problems on the PASS I or to those referred by parents or other professionals.

Child ren who show significant delays on the items of PASS II would then receive careful consideration and possible referral for further diagnosis or assessment. At this stage of the screening process, vision and hearing screening might be wise. A general physical examination may also be considered. Although extreme variability is found among populations of children, probably $10-12 \%$ may indicate the need for further evaluation.

\section{Step 2: Diagnosis}

Diagnosis, within the ABACUS, refers to the process of determining the nature and extent of the problem.
This step in the assessment process is applied to a small subset of the population determined to have some sort of problem. Diagnosis may be done by representatives of the medical or health-related professions. The most common types of diagnostic assessment of young handicapped children are done by pediatricians, neurologists, audiologists, otologists, ophthalmologists, orthopedists, speech and language pathologists, physical or occupational therapists, and the like. With the assistance of these specialists, medical or physiological correlates of the problem may be identified, and programs may be designed to ameliorate them.

Closely related to this type of diagnostic assessment are the psychological assessments done primarily for purposes of eligibility for a special education program. In many states the school psychologist is largely responsible for declaring eligibility for programs for mentally retarded, learning disabled, or emotionally handicapped children. In cooperation with other members of the transdisciplinary team, a child may be declared eligible for the special program. In addition, the school psychologist at this step in the assessment process is to determine the psychological correlates of the disability that are relevant to total assessment of the child.

An estimated $5-10 \%$ of the total population will be declared eligible for special programs because of a handicapping condition. But at this point two questions require answers:

Does a significant developmental delay exist in one or more of the functional life skills, (body management, self-help, communication, pre-academics, or socialization)?

Is a significant discrepancy apparent within the psychological processes that underlie learning (attending, discrimination, visualization, auditorization, concept formation, receptive or expressive language, etc.)?

"Significant delay" for the preschool child may be defined in terms of standard deviations, stanines, or percentiles. On quantifiable measures, a child with a significant delay functions more than 1.5 standard deviations below the mean of his or her age group, or within the lowest $10 \%$ of the population, or in the first or second stanines of norm-referenced measures. Each of these criteria encompasses approximately $8-11 \%$ of the population. The clinical judgment of team members can sharpen the criteria as they relate to a specific child. 
NAME:

BIRTHDATE:
DATE:

TEACHER:

\begin{tabular}{|c|c|c|c|c|c|c|c|c|}
\hline DEVELOPMENTAL AREAS: & 1 & 2 & 3 & 4 & 5 & 6 & 7 & 8 \\
\hline \multicolumn{9}{|l|}{ I. BODY MANAGEMENT } \\
\hline A. Gross Motor & * & * & * & * & * & * & * & * \\
\hline B. Fine Motor & * & $\star$ & * & $*$ & * & * & * & \\
\hline \multicolumn{9}{|l|}{ II. SELF-CARE } \\
\hline A. Dressing & * & * & & & & & & \\
\hline B. Toileting & $*$ & $\star$ & $\star$ & & & & & \\
\hline C. Grooming & * & & & & & & & \\
\hline D. Eating & $\star$ & * & * & & & & & \\
\hline E. Mechanical Know-How & $\star$ & & & & & & & \\
\hline F. Safety & * & & & & & & & \\
\hline \multicolumn{9}{|l|}{ III. COMMUNICATION } \\
\hline A. Prerequisites & $*$ & * & * & * & * & & & \\
\hline B. Comprehension/Produc & * & * & * & * & * & * & * & * \\
\hline
\end{tabular}

IV. PRE-ACADEMICS

RECOMMENDATIONS:

\begin{tabular}{lllll|} 
A. Thinking & $*$ & $*$ & $*$ & $*$ \\
\hline B. Reading & $*$ & $*$ & $*$ \\
\hline C. Mathematics & $*$ & $*$ & $*$ \\
\hline D. Writing & $*$ & $*$ & $*$ & $*$
\end{tabular}

V. SOCIALIZATION

A. Awareness of Self and Others

B. Awareness of Feelings

C. Social Information

D. Play Behavior

E. Interactive Behavior

FIGURE 2

PreABACUS Screening Scale Level II (PASS II) - Face Sheet 
On the Wechsler Preschool and Primary Scale of Intelligence, for example, 1.5 standard deviations below the mean would yield an IQ of 77, with subtest scores of 5 and 6. Although an IQ of 77 would not currently fall within the mentally retarded range, it could indicate a significant discrepancy within the psychological processes that underlie learning and might indicate a learning disability. This would be corroborated if the fullscale score were to reflect some sub-scale scores of 2,3 , or 4 and others of 6,7 , or 8 , or higher. In situations where services can be delivered to "developmentally delayed" children, an IQ of 77 could be indicative of a significant delay.

On measures that cannot be quantified, including many criterion-referenced measures, clinical judgment has to dictate the significance of the delay. Neither criterion-referenced measures nor screening devices should be used to reach eligibility decisions. The clinical judgment of the team may have to be relied upon.

Valid and reliable formal test data on very young children are difficult and often impossible to gather. Thus, the answers to the questions may have to come from structured observations of the child's performance and from informal testing, coupled with formal testing. The family's and the preschool teacher's perceptions and observations have to be heavily emphasized, since the role of the child's support system in ameliorating the impact of biological insult has been documented in longitudinal research.

\section{Step 3: Assessment}

For instructional purposes, assessment is a process for determining the present level of performance and the prioritized goals and objectives in all areas of the curriculum. The total ABACUS assessment device is used at this point - after the child has been accepted into the program and individual programs have begun on the basis of PASS II and other available data.

The ABACUS consists of 209 items, in the five developmental areas mentioned previously:

1. Body Management. This incorporates gross motor skills involving large muscle development (such as sitting, walking, running, climbing, balancing, and throwing) and fine motor skills (grasping objects, stacking blocks, putting pegs in a pegboard, stringing beads, fitting pieces into puzzles, cutting, and the like).
2. Self-Care. The skills involved here are those that allow the child to function independently and to take care of personal needs (dressing, toileting, grooming, eating, mechanical know-how, and safety).

3. Communication. Communication allows for the exchange of ideas or thoughts. The skills involved are divided, in the ABACUS, into prerequisite skills (attending, imitating vocalizations, etc.), comprehension (understanding gestures, words, and concepts), and production (expressing ideas either verbally or through the use of total communication).

4. Pre-Academics. Cognitive skills and knowledge labeled as readiness skills for school can be classified by thinking (e.g., matching objects and pictures, labeling the shape and color of objects), reading (print a wareness, book handling, and reading basic words), mathematics (identifying numbers and numeral concepts 1 to 5), and writing (scribbling, making pre-writing strokes, copying first name, etc.).

5. Socialization. Skills that increase a child's ability to get along with other children and adults and to function and learn in school comprise socialization.

These five developmental areas form the basis for not only the assessment, but the ABACUS curriculum and all components of the system.

During assessment of the child's communication skills using the ABACUS, speech and language pathologists assigned to the program might be called upon to assess language skills beyond those assessed on the ABACUS. A communication sample is taken. It has three major components: content, form, and use. This three-dimensional model of language is basic to describing the development of language and for understanding language delays.

\section{Step 4: Ecological Assessment}

Ecological assessment is defined as a process to determine the physical, environmental, nutritional, and social correlates of the child's problem. It includes maternal perceptions, mother-child interactions, environmental variables, parental attitudes, nutrition, social support systems, and the like. The importance of parental input at this stage is obvious. And data supplied 
by the nurse or social worker might also be useful, with consideration given to specifics such as nutritional status, adequacy of diet, sleeping arrangements at home, and so on.

Questions to be asked are not, "What is wrong with this child?" but, rather: "What does this child need to optimize his or her growth and development? What does the child need from each component of his or her ecosystem in order to survive and thrive?"

In the area of nonorganically defined high-risk infants, toddlers, and preschool youngsters, major efforts have succeeded in producing efficient early detection procedures and effective methods of measuring the effects of early intervention (Garber \& Heber, 1981; Gordon \& Guinagh, 1974; Gutelius, Kirsch, MacDonald, Brooks, McErlearn, \& Newcomb, 1972; Raimey \& Haskins, 1981). Data have been collected on home environments, family support networks, mothers' attitudes and teaching styles, and a host of other psychosocial variables that play a part in programs of early intervention and prevention of functional mental retardation.

Assessment instruments appropriate to ecological aspects of the child's environment have begun to appear in large numbers. One of the first was the Vineland Social Maturity Scale (Doll, 1953), an interview checklist covering socialization, self-help, interpersonal relationships, and other areas. Another scale of interest is Caldwell's (1981) Home Observation for Measurement of the Environment (HOME). A recent home screening questionnaire developed by the John F. Kennedy Child Development Center in Denver (Frankenburg, 1981) provides for gaining similar information on variables in the home that have been found to influence development. These are only examples of many possible choices available.

\section{Step 5: Formulation of an Instructional Hypothesis}

All the data collected in the previous steps (screening data, medical and health-related correlates, psychological correlates, ecological correlates, and educational data) are utilized in formulating a hypothesis upon which instructional decisions are to be based. This hypothesis could be stated succinctly. An example might be:

Although Jose was diagnosed as hydrocephalic at birth, and placed in a home for dying infants at nine days of age, the shunts seem to be working, and the present adoptive home appears to offer adequate support for his emotional needs. The delays present at 4 years of age appear to be residuals of the traumatic first two or three years of life. Current progress has been documented, with gradual closing of the gaps expected as school and home work to ameliorate the delays, and as Jose and his mother become more secure in their relationships. Based on this hypothesis, current levels of functioning will be identified, and the objectives based on what he needs to do next.

This type of statement puts the pieces of an extremely complex assessment process into an organized form that will lead to an instructional program.

\section{Step 6: Development of the Individualized Education Plan}

This final step in the process is based upon all five preceding steps in the total assessment. The decision on eligibility and most appropriate placement now has to be made. If a continuum of services is available, the choice must be based upon the best option to meet the child's individual needs as identified in the assessment process. If a child's prioritized needs can be met in an integrated setting, placement in this less restrictive environment may be indicated. If the prioritized needs indicate that a more intensive individualized program is required, placement in a self-contained class may be called for. In every case, the severity of the child's needs must be matched by the intensity of the service.

The IEP serves as the bridge between assessment and instruction and leads directly into the curriculum. The IEP format developed for the ABACUS incorporates the essential requirements of the federal regulations. Each item in the ABACUS IEP form has a corresponding program in the ABACUS curriculum. Figure 3 is page 3 from the ABACUS IEP form.

The six steps in the assessment process - screening, diagnosis, assessment for instruction, ecological assessment, formulation of an instructional hypothesis, and development of the IEP - should lead smoothly into a curriculum that will help correct developmental delays in the areas of body management, self-care, communication, pre-academics, and socialization. This is the objective of the ABACUS program - to intercede in the lives of children who may be at-risk for later failure, and to direct them in the path of a better life through a systematic, coordinated program of intervention. 


\section{SUMMARY OF PRESENT LEVELS OF PERFORMANCE AND NEED}

Child's Name

For learning period beginning ; ending

BODY MANAGEMENT

Gross Motor:

Fine Motor:

\begin{tabular}{|c|c|c|c|}
\hline $\begin{array}{l}\text { PRESENT LEVEL } \\
\text { OF PERFORMANCE }\end{array}$ & ANNUAL GOAL & $\begin{array}{l}\text { SHORT-TERM } \\
\text { OBJECTIVES }\end{array}$ & DATE MET \\
\hline $\begin{array}{l}\text { Initial assessment indicates } \\
\text { this child is able to: }\end{array}$ & $\begin{array}{l}\text { During this academic year } \\
\text { the child will: }\end{array}$ & $\begin{array}{l}\text { By the end of this learning } \\
\text { period, this child will be } \\
\text { able to: }\end{array}$ & \\
\hline
\end{tabular}




\section{REFERENCES}

Cald well, B. Daily program II-A manual for teachers. Washington, DC: Office of Economic Opportunity, 1965. Also in M. L. Powell, Assessment and management of developmental changes and problems in children (2nd ed.). St. Louis, MO: C. V. Mosby Co., 1981.

Doll, E. A. Vineland social maturity scale. In A. Weider (Ed.), Contributions toward medical psychology: Theory and psychodiagnosis methods (vol. 2). New York: Ronald Press, 1953.

Frankenburg, W. Home screening questionnaire. Denver: John F. Kennedy Development Center/Ladoca, 1981.

Garber, I. J., \& Heber, R. The efficacy of early intervention with family rehabilitation. In M. Begab, H. C. Haywood, \& H. L. Garber (Eds.), Psychosocial influences in retarded performance. Baltimore: University Park Press, 1981.

Gordan, I. J., \& Guinagh, B. J. A home learning center approach to early stimulation (Final report to the National Institute of Mental Health). Gainesville, FL: Institute for Development of Human Resources, University of Florida, 1974.

Gutelius, M. F., Kirsch, A. D., MacDonald, S., Brooks, M. R., McErlearn, T., \& Newcomb, C. Promising results from a cognitive stimulation program in infancy. Clinical Pediatrics, 1972, II, 585-593.

Raimey, C. T., \& Haskins, R. The causes and treatment of school failure: Insights from the Carolina Abecedarian Project. In M. Begab, H. Garber, \& H. C. Haywood (Eds.), Causes and prevention of retarded development in psychosocially disadvantaged children. Baltimore: University Park Press, 1981.

Beverly. Dexter

Lynchburg College

Through our Child Find activities, we have located several preschool children in our district who are "high risk." After the initial screening, we classified these youngsters as potential candidates for special education, although we hesitated to label the children so early. Do you have any suggestions we can offer parents for preparing their children for school during the summer before their initial enrollment - suggestions that might help them and us further assess their child's functioning level?
Parents who have already been alerted about their child's special needs have most likely received some sort of guidelines for working with the child at home, or perhaps they have even received special services through an outside agency. Parents who have suspected that their child has special needs also may have received some form of support services through either private or public agencies. Parents who are not aware of their child's potential special needs, however, may become upset at specific information or advice that comes without warning. Perhaps they have suspected in the back of their minds that their child is a little slower than his or her playmates, but until these suspicions are confirmed without a doubt, they tend to be optimistic and even offended at such a suggestion during initial screening procedures.

In one helpful means of dealing with this potential problem, the district develops a guide for all parents of preschool children, to help them prepare their children for school. The guide could be prepared by the primary teachers as a group so that no area of readiness is overlooked. It should be written in clear, concise sentences for easy interpretation, and each parent should be given a copy when the child is enrolled for kindergarten. The interviewing teacher should openly discuss the printed suggestions and offer further activities that might stimulate growth in specific readiness areas.

A notation and listing should be made of any "highrisk" youngsters. These children should be followed up later in the summer, by encouraging the parents to continue the readiness activities until the beginning of school. The parents should be told at the outset that their children are suspected of having special needs. This should be done in a manner so as to alert rather than alarm the parents. By showing genuine concern for the children and their potential needs, the teacher should be able to gain the support and confidence of these parents.

The suggested guidelines for readiness activities should follow those generally given for all preschoolers, which can be found in most texts about early childhood education. Included in the guidelines should be the following suggestions:

1. Talk with the child about school as a pleasant experience. And don't just talk about the fun to be expected, but also stress the positive experiences, such as meeting new friends and learning how to write his or her name. 
2. Read to your child every day. Let him or her sit on your lap and look at the pictures while you read. Ask the child to find familiar objects in the pictures - a dog, a tree, some flowers, and so on. Encourage him or her to tell you about the objects: "Does that cat look like Fluffy? Why not?" Let the child help you retell the story after hearing it several times, or ask him or her what is going to happen next.

3. Sing to your child and encourage him or her to sing simple songs or hum along with you. The library has books of simple children's songs that may bring back memories from your own childhood. Also, some children's games include songs that you might wish to teach your child. Act out the songs as you sing them. And please don't worry about trying to teach your child to sing like a recording artist. This should be for fun, not for perfection.

4. Encourage your child to talk about familiar activities: "What did you and Kim build in the sandbox?" "What were you playing with at Grandpa's yesterday?"

5. Praise your child for following simple oral directions. Remark on what a big boy or girl he or she is for listening so well to you. Be sure that when you give directions, they are simple and easy enough to follow. You can play simple directionfollowing games like "Simon Says" to help the youngster learn how to listen and follow directions. Take turns letting him or her be the leader for such games.

6. Encourage your child to try quiet, sitting activities during the day. Simple puzzles or take-apart toys can be used during these times, and you can also enjoy working them with your child. Set aside a special place such as a small table for the child to use when working on a puzzle. Buy a coloring book with large, simple pictures in it. Praise your youngster for trying to stay inside the lines when coloring - or outline the figures in black crayon to make the borders easier to see. Provide large pieces of paper (grocery bags cut into rectangles work well) to color or draw on. Let the child draw his or her own pictures, then tape them on the refrigerator door or wall (or door) of the child's room for decoration.

7. Encourage your child to learn how to bounce a large ball, roll it, and even kick it (but only outside). Guide the hands, arms, and feet at first if help is needed. While the child is bouncing the ball, count aloud the number of bounces he or she can do without stopping. Give praise for these efforts, along with encouragement to try again after failing.

8. Teach your child his or her full name (first and last name), and work on having the child say it clearly. Repeat the name while he or she is watching your face, and then let the child say it. Also work on the names of brothers and sisters, as well as other favorite people. The names of pets are also important, and these can be used in sentences such as, "Pookie is my dog." You might also want to teach phone number and address since the child will need to know these later.

9. Encourage your child to use complete sentences when asking for something. If he or she says "Drink" to mean "I want a drink," the child will need to learn "Want drink," then "I want a drink." Once he or she is in school, the child will be asked to tell others about his or her needs. Unless the child can do this, he or she may become frustrated when others cannot understand. Words or phrases that seem "cute" now may become problems later in life. Clear speech should be encouraged at all times.

10. Praise your child's efforts to take care of personal needs. Encourage him or her to try to dress and feed himself or herself. If he or she hasn't been doing these activities, "getting the hang of it" will take a while. In the meantime, socks may be mismatched, shoes may be on the wrong feet, and food may be spilled, but at least the child is trying to become more independent. He or she must also learn how to use the bathroom properly. Can he or she unzip pants without help from an adult? Flush the toilet after using it? Reach the faucet and wash the hands?

The above suggestions are only guidelines for developing a list of activities for parents to work on at home with their children. Each group of teachers should devise their own list of suggestions and incorporate further activities that the parents can do at home to help develop readiness skills in their children. 